\title{
Patterns and costs of hospital care for coronary heart disease related and not related to diabetes
}

\author{
C J Currie, C L Morgan, J R Peters
}

\begin{abstract}
Objective-To describe the epidemiology and costs of coronary heart disease (CHD) requiring hospital admission, with particular reference to diabetes.

Setting-The former South Glamorgan Health Authority, South Wales.

Methods-Routine hospital activity data were record linked and all diabetic and non-diabetic individuals over a four year period (1991-95) were identified. A cost weight was included for each admission based on diagnosis related groups.

Results-There were 10214 patients admitted with a primary diagnostic code for CHD, representing an incidence of 6.3 per 1000 per annum. Including all CHD and non-CHD admissions, these individuals were responsible for $17 \%$ of acute inpatient activity. Men had a consistently higher age specific prevalence of CHD than women. The age adjusted relative risk of CHD for patients with diabetes compared with those without was 4.1 for men and 5.5 for women. Patients with diabetes accounted for $16.9 \%$ of CHD related admissions and had a fourfold increased probability of undergoing a cardiac procedure. The total cost of CHD was estimated to be $6 \%$ of NHS revenue at 1994-95 pay and prices. Patients with diabetes were responsible for $16 \%$ of this expenditure. This translated to an estimated NHS acute hospital expenditure for CHD of $£ 1.1$ billion per year at 1994-95 pay and prices.
\end{abstract}

Conclusions-CHD was responsible for a larger proportion of NHS expenditure than had previously been reported. Nearly one in five acute hospital admissions were for patients whose condition included cardiac problems. The relation between diabetes and CHD was particularly evident, and may offer opportunities for disease prevention.

(Heart 1997;78:544-549)

Keywords: coronary heart disease; diabetes mellitus; cost and cost analysis; epidemiology

Although the relative metabolic contributions to the aetiology of macrovascular complications may be different in diabetes types 1 and 2, accelerated atherosclerosis is consistently associated with hyperglycaemia, dyslipidaemia, and hypertension. ${ }^{1}$ Patients with diabetes have a higher prevalence of hypertension, a higher systolic blood pressure, and greater body mass index (BMI) than the non-diabetic population, ${ }^{2}$ and also increased dyslipidaemia, which may have an important independent effect. ${ }^{3}$ Consequently CHD and cerebrovascular disease account for a 2.5-8-fold increased risk of mortality in the diabetic compared with the non-diabetic population. ${ }^{4}$ In the United States, cerebrovascular disease and CHD account for one third of deaths of patients with diabetes after the age of 40 years. ${ }^{5}$

Prevalence figures for various forms of large vessel disease from a large study ${ }^{6}$ suggest that this was present in $30-40 \%$ of patients with diabetes. A sex related effect has been reported, showing an increased relative risk of CHD for diabetic women over men when compared with the non-diabetic population. The Framingham study showed a relative risk of 2.4 and $5.1,{ }^{7}$ and Barrett-Connor et al found a relative risk of 1.8 and 3.3, respectively for men and women. ${ }^{8}$ There was evidence of greater risk of heart disease in insulin dependent diabetes than noninsulin-dependent diabetes, ${ }^{19}$ which may simply be due to increased lifetime exposure to diabetes related metabolic effects. We have previously reported that patients with diabetes have a crude 12 -fold increased probability of hospital admission for CHD events when compared to the non-diabetic population, and a crude sevenfold increased probability of undergoing a cardiac procedure. ${ }^{10}$

In the present study we have built upon previous work by applying the record linkage technique of probability matching to our data. This identifies all records relating to the same individuals and allows comment on disease prevalence. We have also incorporated a cost weight within each record by assigning each episode to a diagnosis related group.

The objective of this study was to investigate the epidemiology of CHD requiring hospital admission to secondary hospital care, and specifically its relation to diabetes. We also quantified the costs of inpatient care for CHD treatment in the two populations.

\section{Methods}

DATA AND SUBJECTS

All hospital contract minimum datasets for South Glamorgan residents treated anywhere in Wales were examined for a four year period (financial years 1991-92 to 1994-95). Among other details these datasets included primary and subsidiary diagnoses, length of stay, and destination on discharge. Selected diagnoses for the diabetic $v$ non-diabetic populations stratified by age and sex were used. South Glamorgan has a resident population of 


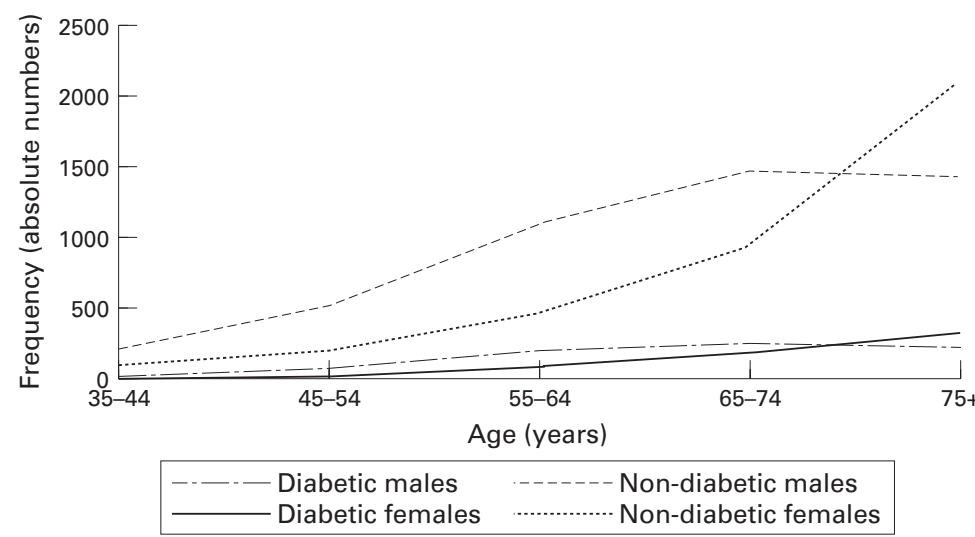

Figure 1 Frequency distribution of patients presenting with a primary diagnosis related to coronary heart disease over a four year period by age and sex.

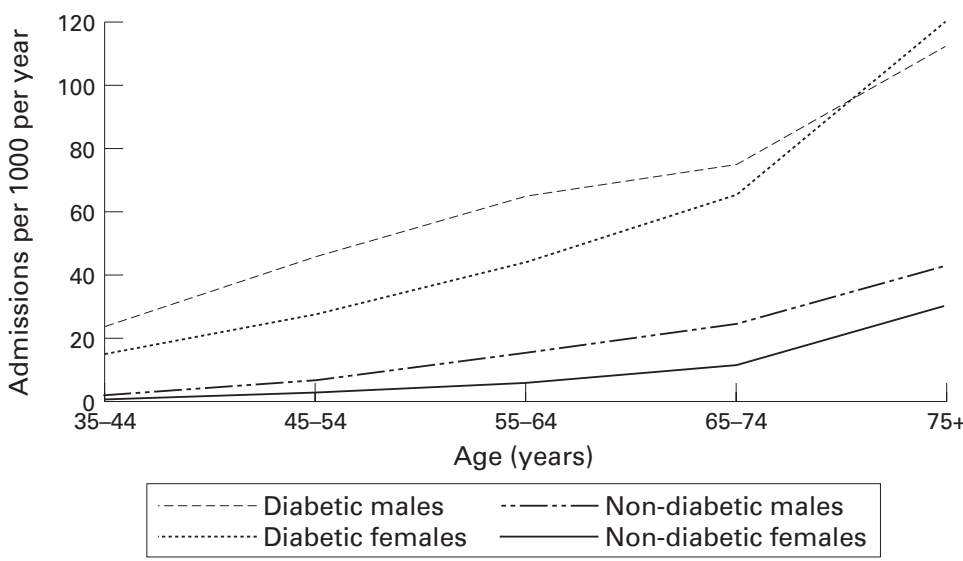

Figure 2 Incidence of coronary heart disease events requiring hospital admission in the diabetic and non-diabetic populations.

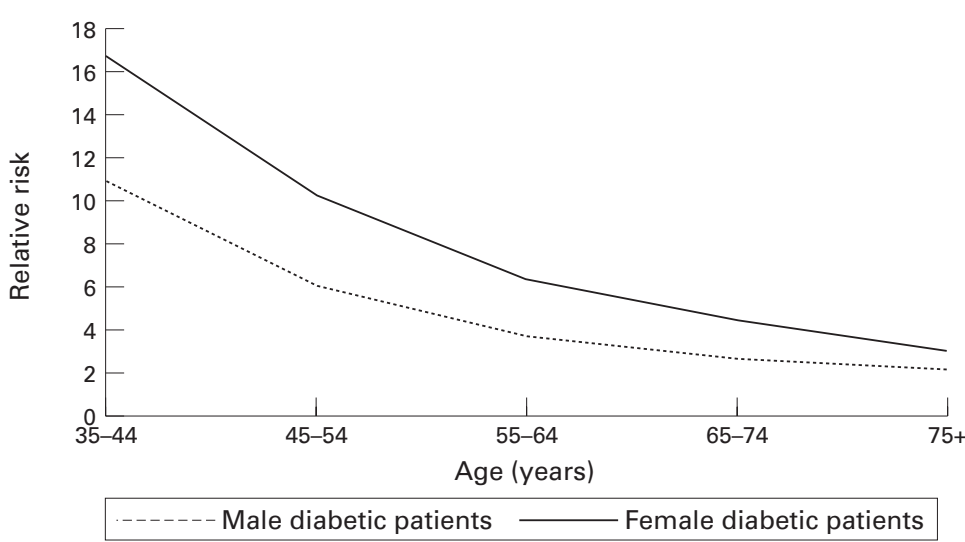

Figure 3 Relative risk of admission for coronary heart disease by age and sex: patients with and without diabetes. of diabetes deduced by inclusion on a diabetic outpatient clinical database; (3) from an appointment at any diabetic outpatient clinic identified from the patient administration system.

\section{RECORD LINKAGE}

Record linkage was carried out using the Oxford record linkage study computer algorithms. ${ }^{11}$ Data relating to the patient identification on each record were probability matched to collate records related to the same individual. A new patient master index was then constructed with a new unique identification number attributed to all routine records referring to the same patient.

\section{SELECTION OF RECORDS DESCRIBING CORONARY} HEART DISEASE

Records were selected where a three character ICD-9 diagnostic code for diagnoses related to CHD was present (ICD-9 codes 410-414, 425-29, and 440). Patients under 35 years of age were excluded to eliminate the small number of patients where the pathology was unlikely to be "genuine" CHD, for example a congenital abnormality may have led to misclassification in one or more of these ICD-9 codes. Although there was a small proportion of incorrectly coded data in all routine datasets, there is empirical evidence that the data available locally are of consistent coding quality. ${ }^{12} 13$

SELECTION OF RECORDS DESCRIBING CARDIAC OPERATIONS

Records were selected where a cardiac procedure unrelated to congenital or valvar heart disease were recorded in one of four operative fields. The coding system used was the OPCS classification of operations and procedures fourth revision (OPCS-4), chapter $\mathrm{K}^{14}$

\section{DETERMINATION OF INPATIENT COSTS}

An estimate of costs was applied to every diabetic and non-diabetic inpatient admission by assigning a cost weight based on the diagnosis related group (DRG) related to each admission. ${ }^{15}{ }^{16}$ These were derived from ICD-9 and OPCS -4 codes, and translated by DRG software (version 12) from the National Casemix Office, Winchester.

\section{DETERMINATION OF EXCESS COSTS}

The purpose of the excess cost calculation was to determine any increased cost of CHD due to the differing risk and probability of admission associated with diabetes.

The excess cost for patients with diabetes was calculated for each individual admission by primary diagnosis (ICD-9 three character code). Excess bed days and costs were determined by first calculating expected values for the diabetic population based on admission rates, lengths of stay, and cost for each diagnostic code (based on the nondiabetic population) and then subtracting these from observed values for each diabetes related admission. 


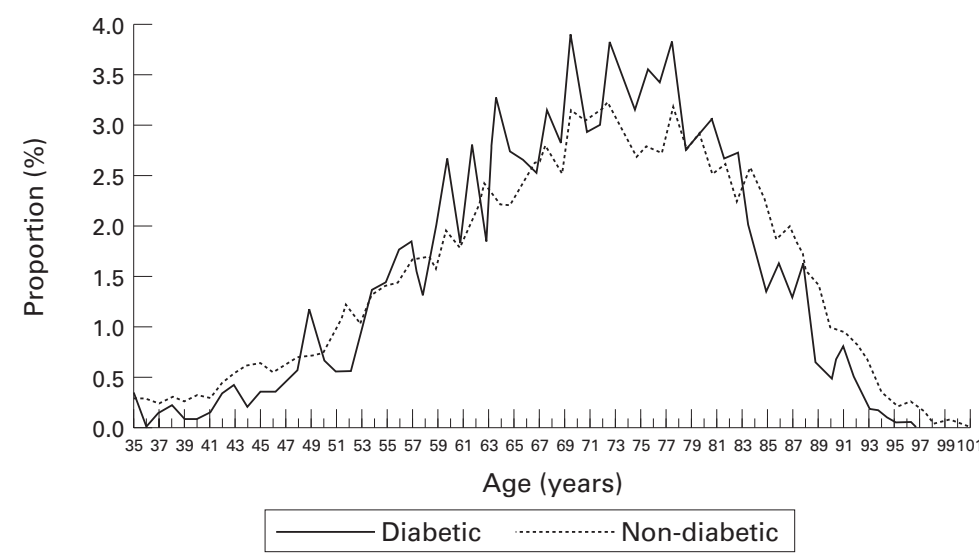

Figure 4 Age related to the proportions of all admissions for coronary heart disease: patients with and without diabetes.

\section{Results}

HOSPITAL ACTIVITY AND DESCRIPTIVE EPIDEMIOLOGY

There were 32220 of 358018 admissions (finished consultant episodes (FCEs)) over the period where a CHD related event was included as a primary or subsidiary diagnosis. This represents $9.0 \%$ of all admissions. Of these admissions, 19090 (59.2\% of 32220 ) had one of the selected ICD-9 categories for $\mathrm{CHD}$ as the primary diagnosis; these accounted for $5.3 \%$ of all hospital admissions (19 090 of 358 018). The 32220 admissions were generated by 15568 individual patients, of whom $10214(66 \%)$ were admitted with a selected ICD-9 code as a primary diagnosis on at least one admission. These two values suggested that there was a crude annual incidence rate of CHD events requiring hospital admission of between 6.3 and 9.5 per 1000 population, depending on whether we used the primary diagnosis alone or also included any subsidiary diagnoses. This value assumed that the number of events remained constant over the four year period and that all admissions relating to an individual referred to the same event. Figure 1 shows the age and sex specific distribution of these patients by their diabetic status. Figure 2 shows the age and sex specific incidence of CHD, and that it was consistently higher in the diabetic population for both men and women. The prevalence of CHD was higher in men than in women in the nondiabetic population; however, within the diabetic population the incidence rate in women exceeded that of males at around 70 years of age.

The 15568 patients whose diagnosis included CHD on one or more of their routine records accounted for a further 28560 admissions over the same period where CHD was not recorded. This would suggest that these patients- $3.8 \%$ of the population - are responsible for over $17.0 \%$ of all acute inpatient activity.

Dealing specifically with only the 10214 cases with CHD recorded as a primary diagnosis, $1484(11.5 \%)$ also had diabetes and were responsible for $3119(16.3 \%)$ of all CHD related hospital admissions. The mean number of CHD admissions per patient over the study period was 2.1 for patients with diabetes and 1.8 for those without. The age adjusted relative risk of being admitted with a primary diagnosis of CHD was 4.1 for males and 5.5 for females. Figure 3 shows the sex specific relative risk by age group: diabetic males and females at 40 years of age had a 10-fold and a 16-fold increased risk, respectively, of being admitted with a CHD event compared with the nondiabetic population. This increased relative risk for females compared with males was maintained in each age group. In the elderly (75+ years) the relative risk was 3.9 in the diabetic female population and 2.1 in the diabetic male population. Figure 4 shows patients with and without diabetes as a proportion of all CHD admissions by age. The average age on admission for both patients with and without diabetes was 69 years.

\section{PROCESS MEASURES}

The number of admissions and associated length of stay for CHD are shown by destination on discharge (table 1) and primary

Table 1 Admissions and length of stay by destination on discharge

\begin{tabular}{|c|c|c|c|c|c|c|c|c|c|c|}
\hline \multirow[b]{2}{*}{$\begin{array}{l}\text { Destination on } \\
\text { discharge }^{\star}\end{array}$} & \multicolumn{2}{|c|}{ Admissions } & \multicolumn{2}{|c|}{ Total bed days } & \multicolumn{3}{|c|}{ Average length of stay (days) } & \multicolumn{3}{|l|}{ Patients } \\
\hline & Diabetic & Non-diabetic & Diabetic & Non-diabetic & Diabetic & Non-diabetic & Difference & Diabetic & Non-diabetic & $\begin{array}{l}\text { Relative risk } \\
(95 \% \text { CI })\end{array}$ \\
\hline $\begin{array}{l}\text { Usual place of } \\
\text { residence }\end{array}$ & 2570 & 13396 & 20584 & 96409 & 8.0 & 7.2 & 0.8 & 1249 & 7437 & $0.98(0.97$ to 1.00$)$ \\
\hline $\begin{array}{l}\text { Temporary place of } \\
\text { residence }\end{array}$ & 5 & 10 & 74 & 161 & 14.8 & 16.1 & -1.3 & 2 & 10 & $2.56(0.88$ to 7.49$)$ \\
\hline Special hospital & 5 & 12 & 66 & 166 & 13.2 & 13.8 & -0.6 & 4 & 10 & $2.13(0.75$ to 6.05$)$ \\
\hline $\begin{array}{l}\text { Other NHS provider } \\
\text { Other NHS } \\
\text { provider-mentally } \\
\text { ill/handicapped }\end{array}$ & 122 & 623 & 1162 & 14658 & 9.5 & 23.5 & -14.0 & 96 & 471 & $1.00(0.83$ to 1.21$)$ \\
\hline $\begin{array}{l}\text { ward } \\
\text { Under local authority }\end{array}$ & 1 & 7 & 20 & 167 & 20.0 & 23.9 & -3.9 & 1 & 7 & $0.73(0.09$ to 5.94$)$ \\
\hline $\begin{array}{l}\text { care } \\
\text { Deaths including }\end{array}$ & 5 & 29 & 78 & 593 & 15.6 & 20.4 & -4.8 & 5 & 24 & $0.88(0.34$ to 2.28$)$ \\
\hline $\begin{array}{l}\text { Deaths including } \\
\text { stillbirths } \\
\text { Other non-NHS }\end{array}$ & 370 & 1685 & 3301 & 17053 & 8.9 & 10.1 & -1.2 & 313 & 1430 & $1.12(1.01$ to 1.25$)$ \\
\hline $\begin{array}{l}\text { hospital, residential } \\
\text { care, nursing home } \\
\text { Uncoded }\end{array}$ & $\begin{array}{l}21 \\
20\end{array}$ & $\begin{array}{r}94 \\
115\end{array}$ & $\begin{array}{r}253 \\
81\end{array}$ & $\begin{array}{l}2054 \\
5672\end{array}$ & 12.0 & $\begin{array}{l}21.9 \\
49.3\end{array}$ & $\begin{array}{r}-9.8 \\
-45.3\end{array}$ & 14 & $\begin{array}{l}70 \\
83\end{array}$ & $1.14(0.71$ to 1.83$)$ \\
\hline Uncoded & 20 & 115 & 81 & 5672 & 4.1 & 49.3 & -45.3 & 15 & 83 & $0.89(0.55$ to 1.43$)$ \\
\hline Total & 3119 & 15971 & 25619 & 136933 & 8.2 & 8.6 & -0.4 & 1699 & 9542 & \\
\hline
\end{tabular}

${ }^{\star}$ Some events will generate two admissions, hence duplicate discharge destinations; CI, confidence interval. 
Table 2 Admissions and length of stay by primary diagnosis

\begin{tabular}{|c|c|c|c|c|c|c|c|c|c|c|c|}
\hline \multirow[b]{2}{*}{ Code } & \multirow[b]{2}{*}{ Primary diagnosis } & \multicolumn{2}{|c|}{ Admissions } & \multicolumn{2}{|c|}{ Total bed days } & \multicolumn{3}{|l|}{ Average } & \multicolumn{3}{|l|}{ Patients } \\
\hline & & Diabetic & Non-diabetic & Diabetic & Non-diabetic & Diabetic & Non-diabetic & Difference & Diabetic & Non-diabetic & $\begin{array}{l}\text { Age standardised } \\
\text { relative risk }(95 \% \text { CI })\end{array}$ \\
\hline A410 & $\begin{array}{l}\text { Acute myocardial } \\
\text { infarction }\end{array}$ & 681 & 3492 & 4950 & 25996 & 7.3 & 7.4 & -0.2 & 464 & 2527 & $5.83(4.83$ to 5.99$)$ \\
\hline A411 & $\begin{array}{l}\text { Other acute and } \\
\text { subacute forms of } \\
\text { IHD } \\
\text { Old myocardial }\end{array}$ & 140 & 531 & 857 & 2932 & 6.1 & 5.5 & 0.6 & 67 & 321 & $6.95(5.27$ to 9.16$)$ \\
\hline & infarction & 1 & 15 & 6 & 73 & 6.0 & 4.9 & 1.1 & 1 & 12 & $3.11(0.40$ to 23.92$)$ \\
\hline A 413 & Angina pectoris & 557 & 2950 & 2787 & 13881 & 5.0 & 4.7 & 0.3 & 348 & 2001 & $5.35(4.74$ to 6.04$)$ \\
\hline A414 & $\begin{array}{l}\text { Other forms of } \\
\text { chronic IHD }\end{array}$ & 414 & 2354 & 3069 & 14381 & 7.4 & 6.1 & 1.3 & 298 & 1663 & $5.23(4.57$ to 5.99$)$ \\
\hline $\begin{array}{l}\text { A425 } \\
\text { A426 }\end{array}$ & $\begin{array}{l}\text { Cardiomyopathy } \\
\text { Conduction }\end{array}$ & 21 & 164 & 220 & 986 & 10.5 & 6.0 & 4.5 & 17 & 108 & $5.68(3.24$ to 9.90$)$ \\
\hline A427 & $\begin{array}{l}\text { disorders } \\
\text { Cardiac }\end{array}$ & 52 & 315 & 355 & 6543 & 6.8 & 20.8 & -13.9 & 37 & 205 & $4.62(3.03$ to 7.05$)$ \\
\hline & arrhythmias & 282 & 2230 & 1895 & 16610 & 6.7 & 7.4 & -0.7 & 198 & 1568 & $3.26(2.73$ to 3.89$)$ \\
\hline A 428 & Heart failure & 922 & 3684 & 10773 & 52404 & 11.7 & 14.2 & -2.5 & 509 & 2211 & $5.84(4.89$ to 6.14$)$ \\
\hline A429 & $\begin{array}{l}\text { Ill defined } \\
\text { descriptions and } \\
\text { complications }\end{array}$ & 16 & 93 & 208 & 1401 & 13.0 & 15.1 & -2.1 & 13 & 65 & $4.90(2.34$ to 10.23$)$ \\
\hline A 440 & Atherosclerosis & 33 & 143 & 499 & 1726 & 15.1 & 12.1 & 3.1 & 29 & 117 & $8.34(5.41$ to 12.85$)$ \\
\hline & Total & 3119 & 15971 & 25619 & 136933 & 8.2 & 8.6 & -0.4 & 1981 & 10798 & \\
\hline
\end{tabular}

CI, confidence interval; IHD, ischaemic heart disease.

diagnosis (table 2). The average length of stay for CHD related primary diagnoses was almost identical, at 8.2 and 8.6 days for the diabetic and non-diabetic population, respectively. For those patients who did not survive to discharge, the average stay was slightly longer in both populations-8.9 and 10.1 days, respectively. There were 4173 admissions for acute myocardial infarction (ICD-9 code 410), of whom 619 $(14.8 \%)$ were patients with diabetes. The mean length of stay in these patients was again almost identical, at slightly over seven days. In contrast, the largest difference in mean length of stay was for conduction disorders (ICD-9 code 426) with a length of stay of 6.8 days for patients with diabetes compared with 20.8 days for the non-diabetic population, although this diagnosis accounted for under $2 \%$ of total CHD admissions. The crude mean length of stay for all 358018 admissions was 5.7 days9.4 for patients with diabetes and 5.5 for those without.

The case fatality rate from CHD for patients with diabetes was $18.4 \%$ compared with $15.0 \%$ for the non-diabetic population. The

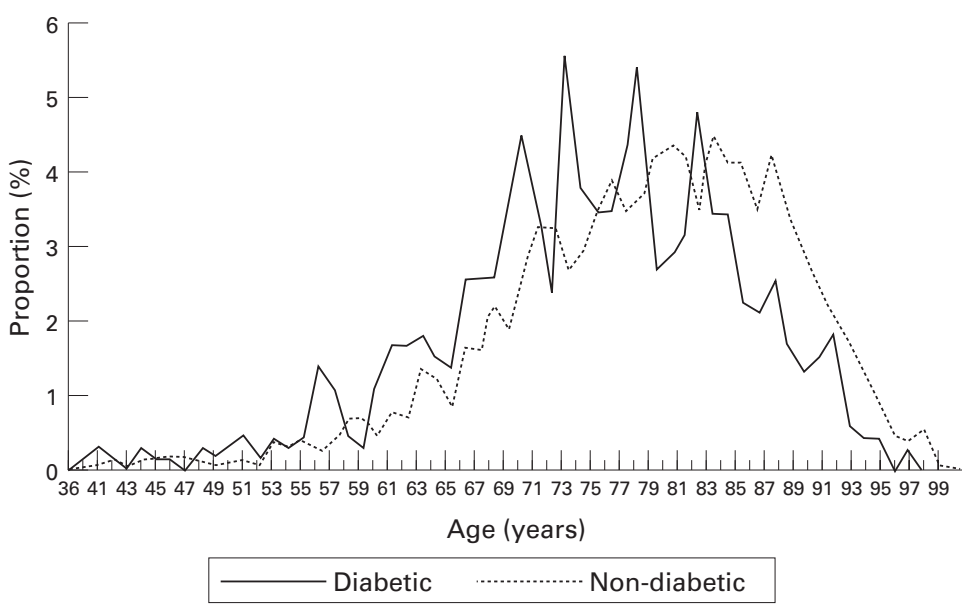

Figure 5 Age at death related to the proportion of all coronary heart disease deaths: patients with and without diabetes. average age of those patients who did not survive to discharge was 74 years for those with diabetes and 76 for those without. The spread of age at death as a proportion of deaths in each group is shown in fig 5 .

\section{CARDIAC PROCEDURES}

Over the same period there were 4415 cardiac operations recorded as a primary procedure$12.3 \%$ for patients with diabetes (table 3 ). These procedures were carried out on 3274 individuals, of whom $401(12.2 \%)$ had diabetes. The age adjusted relative risk of a patient with diabetes undergoing a procedure when compared to a patient without diabetes was 4.15 (95\% confidence interval (CI), 3.63 to 4.74 ) for men, and 4.76 (95\% CI, 3.91 to 5.80) for women. Table 3 shows these relations by type of procedure. There was wide variation in the male to female probability of undergoing a procedure. The crude relative risk of a male undergoing a cardiac procedure compared with a female was 1.30 (95\% CI, 1.26 to 1.34 ); however, this was dependent on the type of procedure. For example, pacemakers were fitted in similar proportions, whereas males were far more likely to undergo saphenous vein graft of artery (relative risk 3.23 (95\% CI, 2.57 to 4.07$)$ ). Table 4 shows the average age for the main cardiac procedures performed for both diabetic and non-diabetic patients. For all cardiac procedures the average age was 64 years for patients with diabetes and 60 for those without.

HOSPITAL COSTS AND EXCESS COSTS

In this locality, with a resident population of 408000 people, the estimated cost of acute care for admissions with a primary diagnosis of CHD was $£ 34$ million over a four year period at 1994-95 pay and prices. This came to approximately $£ 8$ million per year, or alternatively $£ 2$ million per 100000 population per year. The cost of the two most common causes of admission (acute myocardial infarction and heart failure) was $£ 0.7$ million per 100000 


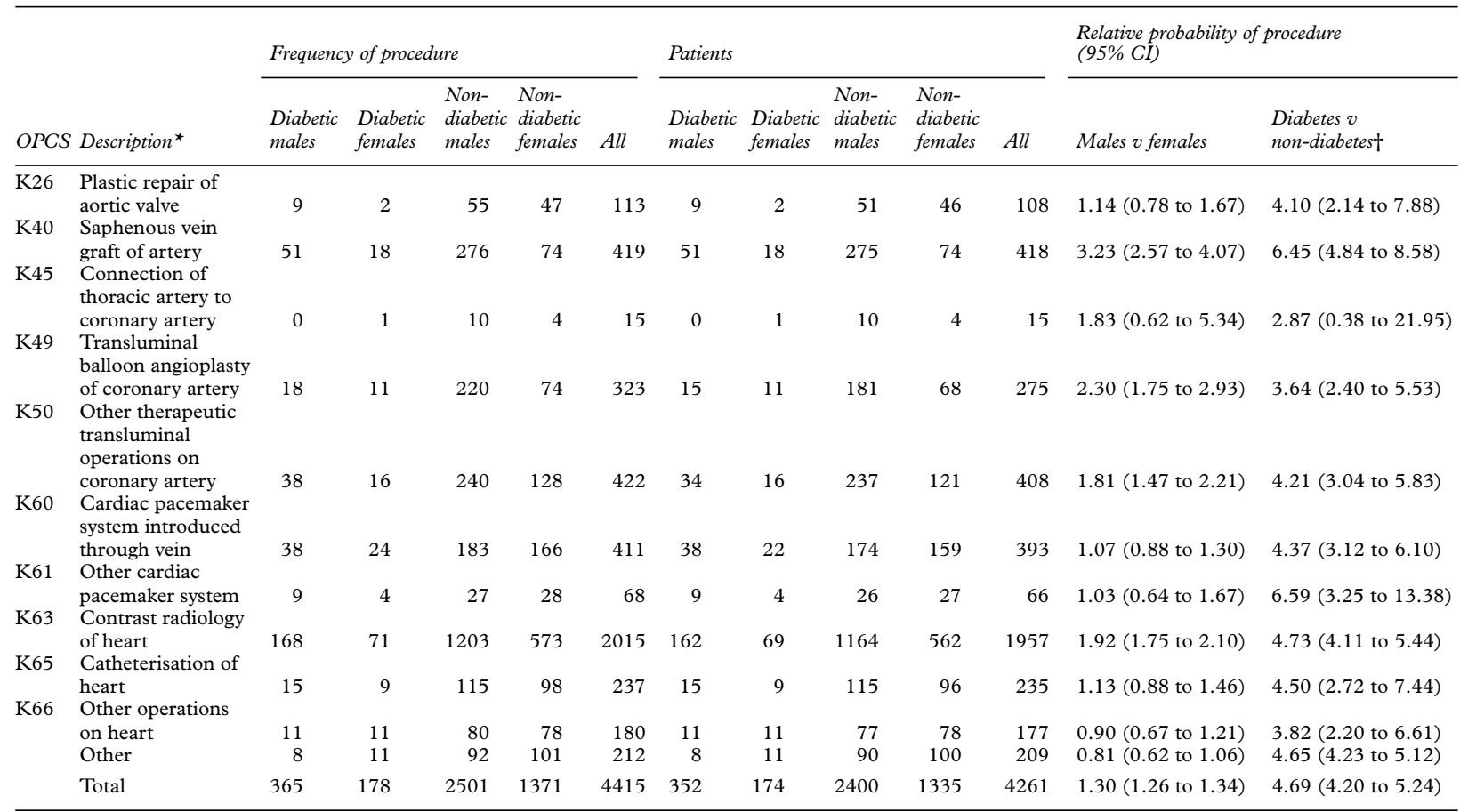

^Some patients will have more than one type of procedure.

†Relative probability of admission, diabetes $v$ non-diabetes, has been standardised for age.

Table 4 Mean age for cardiac procedures

\begin{tabular}{|c|c|c|c|c|}
\hline OPCS & Description & Diabetic & Non-diabetic & Difference \\
\hline K26 & Plastic repair of aortic valve & 67.0 & 71.6 & 4.6 \\
\hline K40 & Saphenous vein graft of valve or artery & 62.7 & 62.5 & -0.2 \\
\hline K45 & $\begin{array}{l}\text { Connection of thoracic artery to } \\
\text { coronary artery }\end{array}$ & 62.0 & 56.6 & -5.4 \\
\hline K49 & $\begin{array}{l}\text { Transluminal balloon angioplasty of } \\
\text { coronary artery }\end{array}$ & 60.6 & 58.3 & -2.2 \\
\hline K50 & $\begin{array}{l}\text { Other therapeutic transluminal } \\
\text { operations on coronary artery }\end{array}$ & 66.6 & 64.4 & -2.3 \\
\hline K60 & $\begin{array}{l}\text { Cardiac pacemaker system introduced } \\
\text { through vein }\end{array}$ & 74.6 & 74.4 & -0.2 \\
\hline K61 & Other cardiac pacemaker system & 74.0 & 77.5 & 3.5 \\
\hline K63 & Contrast radiology of heart & 61.3 & 60.4 & -0.8 \\
\hline K65 & Catheterisation of heart & 63.5 & 60.2 & -3.3 \\
\hline K66 & Other operations on heart & 70.4 & 67.4 & -3.0 \\
\hline & All cardiac procedures & 64.1 & 60.1 & -4.1 \\
\hline
\end{tabular}

population per year, and £0.5 million per 100000 population per year, respectively.

Admission of patients with CHD who also had diabetes cost $17 \%$ of $\mathrm{CHD}$ related expenditure. Moreover, some $80 \%$ of this expenditure ( $£ 4.6$ million of $£ 5.7$ million over four years) would not have been expected had the diabetic population had the same probability of admission and an identical mean length of stay to the non-diabetic population. ${ }^{10}$ This was therefore an excess cost and may potentially be avoidable.

\section{Discussion}

The aim of this study was to describe the epidemiology and costs of CHD requiring hospital admission, with particular reference to diabetes. To achieve this we analysed routinely collated hospital data. This approach is fraught with potential sources of bias, especially when considering a disease such as diabetes which was often omitted as a subsidiary diagnostic code. In addition, the absence of systems for routine financial analysis by case severity in the NHS reduces the ease of robust and flexible cost analysis. ${ }^{17}$ These data do not normally allow reliable epidemiological analysis since first, there may not be a direct relation between activity rates and the number of individual patients, and second, some patients will be assigned different identities on separate clinical contacts, that is, they receive more than one hospital case record number. We developed methods to address these difficulties which allowed us to examine both the epidemiology and costs of care for a large resident population, with validated age and sex specific diabetes prevalence data. ${ }^{18}$

While the overall community prevalence of CHD was undoubtedly higher, we excluded sex bias in admission criteria as a confounding factor. ${ }^{19}$ Within the study population the presence of diabetes as a comorbidity represented an age adjusted relative risk of being admitted with heart disease of 4.1 and 5.5 for men and women, respectively. Figures 1 and 2 show the absolute number of cases by age and sex, and the age related incidence based on these numbers. These show that although there is a widely recognised age related decrease in the absolute number of male patients with CHD after the age of 65 years, the incidence of events requiring admission within the remaining male population was still greater than that of the female population. One third of all elderly males (75 years and older) will have had a hospital admission where CHD has been included as a diagnosis. The age specific increase in the incidence of events was similar in both the diabetic and non-diabetic populations, but the absolute number of men and women with CHD in both populations was the same at 70 
years of age (fig 1). The tailing off of incidence in the male diabetic population may have been related to earlier development of $\mathrm{CHD}$ and earlier mortality in that proportion of the male diabetic population susceptible to CHD (see fig 5).

The similarity in diagnosis specific mean length of stay was somewhat surprising, since we knew that the crude mean length of stay in our total diabetic population was 9.4 days versus 5.5 days in the non-diabetic population. ${ }^{10}$ This suggests similar case severity in these acutely unwell patient groups. The increased mean number of admissions per diabetic patient compared with each non-diabetic patient may indicate a decreased admission threshold for diabetic patients with CHD, associated with a shorter length of stay in this diagnostic subgroup.

The mean age on admission for patients with and without diabetes was the same, at 69 years, but fig 4 shows a slightly wider spread for those patients without diabetes. Similarly the mean age of those who did not survive to discharge was 74 years for patients with diabetes and 76 without. Cardiac procedures tend to be performed slightly later on diabetic patients.

Our analyses showed that at least $15 \%$ of patients admitted with CHD underwent an invasive cardiac procedure within the study period. After standardising for age, there was over a fourfold increase in the probability of a patient with diabetes undergoing a heart operation compared to those without diabetes, highlighting the increased level of cardiac disease in this patient group. Additionally, men are twice as likely as women to have an heart operation. The hypothesis that there may have been some form of sex discrimination in the assessment of suitability for cardiac surgery ${ }^{20}$ was supported by the observation that the relative sex related probability of undergoing a "less negotiable" procedure, for example cardiac pacing, was the same for both sexes. Conversely, there was more variation in the relative probability of undergoing a procedure more open to clinical discretion. There is also a clinical issue relating to the greater suitability of men to undergo certain forms of cardiac surgery because of differing cardiovascular physiology.

The cost of CHD to the NHS was estimated at $£ 500$ million in $1989,{ }^{21}$ and $£ 332$ million in $1991 .^{22}$ The cost of CHD, at around $£ 8$ million per year within our authority, constitutes almost $6 \%$ of acute revenue expenditure. If extrapolated to England and Wales, data here suggest a total NHS expenditure for CHD of at least $£ 1.1$ billion. If this is the case, the inpatient cost of CHD was significantly underestimated. People with diabetes were responsible for $17 \%$ of this expenditure which nationally represents some $£ 187$ million. Moreover, because of the increased risk that diabetes con- tributes to the likelihood of developing CHD, $80 \%$ (the excess cost) of this diabetes-CHD related expenditure could be reduced, since the adverse influences of the diabetic state on other complications are known to be modifiable. ${ }^{23} 24$

CC and CM are funded by the British Diabetic Association, and we would like to thank them for their continued support. We would also like to thank Mr Leicester Gill (Unit of Health Care Sciences, University of Oxford) for help with the record linkage, and Professor Nigel Stott (Department of General Practice, University Wales College of Medicine) for supplying data from the audit of diabetes in general practice.

1 McKeigue PM, Keen H. Diabetes, insulin, ethnicity, and coronary heart disease. In: Marmot M, Elliot P. $C H D$ epidemiology: from aetiology to public health. Oxford: Oxford Medical Publications, 1995:217-32.

2 WHO Monica Project. Geographical variation in the major risk factors in CHD in men and women aged 35-64. World Health Stat $Q$ 1988;41:115-40.

3 Jones SL, Close CF, Mattock MB, Jarrett RJ, Keen H, Viberti GC. Plasma lipid and coagulation factor concentration in insulin dependent diabetics with microalbuminuria. in insulin dependent

4 Veikko S, Tuomilehto J. Diabetes and macrovascular diseases. In: Williams R, Papoz L, Fuller J, eds. Diabetes in diseases. In: Williams R, Papoz L, Fuller J,
Europe. London: John Libbey, 1995:46-55.

5 Barrett-Connor E, Orchard T. Diabetes and heart disease. Diabetes in America 1984. (NIH Publication No 85-1468.) Bethesda, 1985: chapter XVI:1-41.

6 Diabetes Drafting Group (1985). Diabetes and macrovascular diseases. In: Williams R, Papoz L, Fuller J, eds. Diabetes in Europe. London: John Libbey, 1995:46-55.

7 Kannel WB. Lipids, diabetes and coronary heart disease: insights from the Framingham Study. Am Heart 1985;110:1100-7.

8 Barrett-Connor EL, Cohn BA, Wingard DL, Edelstein SL. Why is diabetes mellitus a stronger risk factor for fatal ischaemic heart disease in women than in men? The Rancho Bernardo Study. ҰAMA 1991;265:627-31.

9 Krolewski AS, Kosinski EJ, Warram JH, Leland OS, Busick EJ, Asmal AC, et al. Magnitude and determinants of CHD in juvenile onset, insulin dependent diabetes mellitus. Am $\mathcal{F}$ in juvenile onset, insulin

10 Currie CJ, Williams R, Peters JR. Patterns of in and out-patient activity for diabetes: a district survey. Diabetic Med 1996;13:273-80.

11 Gill L, Goldacre M, Simmons H, Bettley G, Griffith M. Computerised linking of medical records: methodological guidelines. F Epidemiol Community Health 1993;47:316-19.

12 Llandough Hospital Data Audit Project. Cardiff: Health Intelligence Unit, Welsh Health Common Services Authority, August 1992 .

13 Wilkinson EJ, Harvey I. Accuracy of hospital diagnostic and operative procedure coding. In: Commentaries on health services Cardiff: South Glamorgan Health Authority, 1990:119-21.

14 Office of Population Censuses and Surveys. Tabular list of the classification of surgical operations and procedures. London: HMSO, 1990.

15 Bardsley M, Coles J, Jenkins L, eds. DRGs and health care. The management of casemix. London: King Edward's Hospital Fund for London, 1987.

16 Söderlund N, Milne R, Gray A, Raftery J. Differences in hospital casemix, and the relationship between casemix and hospital costs. F Public Health Med 1995;17:25-32.

17 Currie CJ, Peters JR. Routine health information in the NHS: missed opportunities. Br F Healthcare Comput Inform Manage 1995;12:26-8.

18 Butler C, Peters JR, Stott N. Glycated haemoglobin and metabolic control of diabetes mellitus: external versus locally established clinical targets. BMf 1995;310:784-8.

19 Currie CJ, Peters JR. Gender and coronary heart disease: the relative probability of dying in hospital. Heart 1997;77: $371-2$.

20 Petticrew M, McKee M, Jones J. Coronary artery surgery: are women discriminated against? BMF 1993:306:1164-6.

21 House of Commons Committee of Public Accounts, Session 1988-89. Twenty-sixth report: Coronary heart disease. London: HMSO, 1989.

22 Office of Health Economics. Compendium of health statistics, 8th ed. London: Office of Health Economics, 1992

23 Diabetes Control and Complications Trial. The effect of intensive treatment of diabetes on the development and progression of long-term complications in insulindependent diabetes mellitus. N Engl F Med 1993;329:97786.

24 Effective intensive diabetes management on macrovascular events and risk factors in the Diabe 75:894-903. 